\title{
Enantioconvergent alkylation of ketones with racemic secondary alcohols via hydrogen borrowing catalysis
}

Received 00th January 20xx, Accepted 00th January 20xx DOI: $10.1039 / \times 0 \times x 00000 x$
Daniella M. J. Cheang, ${ }^{a}$ Roly J. Armstrong, ${ }^{a}$ Wasim M. Akhtar ${ }^{\mathrm{a}}$ and Timothy J. Donohoe*a
An enantioconvergent method for the alkylation of o-disubstituted aryl ketones with racemic secondary alcohols is described. This process is mediated by a commercially available iridium catalyst and proceeds via hydrogen borrowing catalysis. The highly enantioenriched $\beta$-substituted ketone products were readily cleaved to a wide range of functional groups via retroFriedel-Crafts acylation.

The synthesis of architecturally complex 3D scaffolds rich in stereogenic centres necessitates development of efficient strategies which construct $\mathrm{C}\left(\mathrm{sp}^{3}\right)-\mathrm{C}\left(\mathrm{sp}^{3}\right)$ bonds and ensure high levels of stereocontrol. In this regard the development of new methods to synthesise enantioenriched molecules remains a fundamental challenge in organic chemistry. Most synthetic approaches developed to date rely upon construction of new stereogenic centres from prochiral substrates or resolution of racemic precursors. ${ }^{1}$ Enantioconvergent catalysis represents a powerful alternative strategy; one in which a racemic starting material can undergo loss of stereochemical information during a reaction and thereby converge to form a single enantiomer of product in up to $100 \%$ yield, overcoming the inherent inefficiency of kinetic resolution. ${ }^{2}$

Several elegant processes have been developed in which racemic alkyl halides (or pseudohalides) undergo enantioconvergent alkylation with nucleophiles (Scheme 1A). A variety of approaches have been employed to facilitate such reactions including asymmetric alkylation of allylic electrophiles, ${ }^{3}$ transition-metal catalyzed cross-coupling, ${ }^{4}$ and photoredox catalysis. ${ }^{5}$ Despite the extensive utility of this approach, the need for toxic, pre-functionalised electrophiles remains a significant limitation. In the context of $\mathrm{C}-\mathrm{N}$ bond formation, Zhao and co-workers have recently disclosed an elegant solution to this problem, reporting a process involving the enantioconvergent alkylation of amines with unactivated secondary alcohols (Scheme 1B).6,7 This reaction is mediated

a. Chemistry Research Laboratory, University of Oxford, Mansfield Road, Oxford, OX1 3TA, UK.

Electronic Supplementary Information (ESI) available: Detailed experimental procedures and characterization data for new compounds. See DOI: $10.1039 / x 0 x x 00000 x$ by a combination of iridium and phosphoric acid catalysts and operates by hydrogen borrowing catalysis. Our group and others have demonstrated that hydrogen borrowing catalysis can also be applied to the formation of $\mathrm{C}-\mathrm{C}$ bonds using enolate nucleophiles. ${ }^{8}$ However, despite numerous advances in this field, no general methods have been reported to control the absolute stereochemical outcome of the process. ${ }^{9}$ Very recently, we reported an asymmetric method for the synthesis of enantioenriched cyclohexanes from 1,5-diols and ketones. ${ }^{10}$ Inspired by this approach, we speculated that it may be possible to apply a related strategy to the enantioselective synthesis of acyclic ketones via enantioconvergent alkylation of enolates with secondary alcohols.

\section{A. Enantioconvergent alkylation}

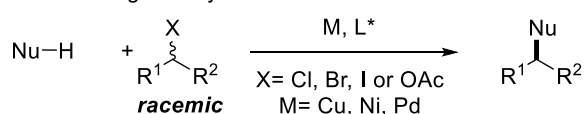

B. Zhao: Enantioconvergent hydrogen borrowing alkylation of amines

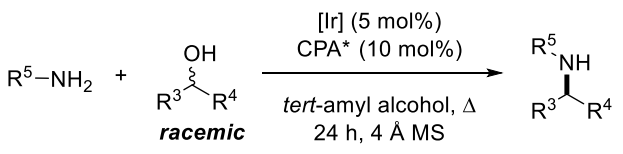

C. This work: Enantioconvergent alkylation of ketones with alcohols

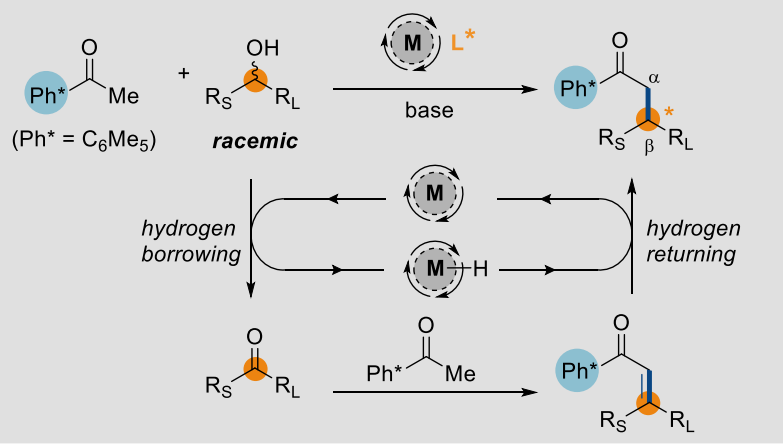

Scheme 1. Previous work and strategy for enantioconvergent alkylation of ketones with alcohols via hydrogen borrowing catalysis.

Our proposed strategy for this process is outlined in Scheme 1C. The reaction would be initiated by dehydrogenation of a 
racemic alcohol forming the corresponding ketone in situ, which could then undergo aldol condensation with pentamethylacetophenone to generate an achiral enone intermediate. The enantiodetermining step would then involve asymmetric reduction of this enone by the metal hydride to release the enantioenriched ketone product and close the catalytic cycle. There is good precedent for the asymmetric reduction of trisubstituted enones, but from the outset we were aware that a key challenge would have to be addressed before success could be achieved. ${ }^{11}$ Namely, to achieve high levels of enantioselectivity, it is critical that the enone intermediate is formed as a single geometric isomer. Here we report how we were ultimately able to overcome this challenge and develop an enantioconvergent alkylation to form $\beta$-branched acyclic ketones.

Following optimization, we were delighted to find that pentamethylacetophenone $\mathbf{1}$ could be reacted with alcohol $\mathbf{2 a}$ in the presence of $\operatorname{Ir}(\mathrm{cod}) \mathrm{acac}(4 \mathrm{~mol} \%),(R)$-DTBM-SEGPHOS (4) $(5 \mathrm{~mol} \%), \mathrm{NaO}{ }^{t} \mathrm{Bu}$ (4 equiv) in ${ }^{t} \mathrm{BuOH}$ at $110^{\circ} \mathrm{C}$ to afford the desired product $3 a$ in 91\% yield and 90:10 e.r. (Table 1, Entry 1). A simplified ligand, ( $R$ )-SEGPHOS (5), resulted in a drastic reduction in yield and enantioselectivity (Table 1, Entry 2). To probe this effect more thoroughly we switched to the MeOBIPHEP backbone, due to the commercial availability of a range of P-Ar derivatives. (R)-DTBM-MeO-BIPHEP (6) gave a similar yield to the optimal conditions, albeit with a small decrease in enantioselectivity (Table 1, Entry 3). Interestingly removing the methoxy group (ligand 7 ) gave a drastic reduction in enantioselectivity and 3a was formed in 68:32 e.r. (Table 1, Entry 4). We observed similar enantioselectivity (79:21 e.r.) when the bulky tert-butyl groups of the ligand were replaced with methoxy groups (c.f. 7 with 8), along with reduced yield (Table 1, Entry 5). Unsubstituted (R)-MeOBIPHEP (9) resulted in low yield and enantioselectivity, similar to the result obtained with (R)-SEGPHOS (5). Taken in conjunction these results suggest that the P-Ar group of the ligand must be both sterically bulky and electron rich to ensure both high yields and enantioselectivities. Other ligands such as (R)-Monophos performed poorly in the reaction (Table 1, Entry 7). Full details for all ligand optimisation are provided in the Supplementary Information. Other metal precatalysts based on $\mathrm{Rh}$ and $\mathrm{Ru}$ led to reduced enantioselectivity (Table 1, entries 8-9). Interestingly the reaction is highly sensitive to the nature of the base: both $\mathrm{NaOH}$ and $\mathrm{KOH}$ proved detrimental and surprisingly we observed significantly lower yield with potassium tert-butoxide (Table 1, entries 10-12).

With optimal conditions in hand, we set out to investigate the generality of the process. It rapidly became evident that decreasing the size of the large substituent $\left(R_{L}\right)$ had $a$ detrimental effect upon enantioselectivity. For example, using an alcohol in which the tert-butyl group is replaced with a less sterically encumbered neopentyl group resulted in formation of ketone 3b in 63:37 e.r. albeit still with good yield. We hypothesise that a bulky substituent favours formation of a single geometrical isomer of the key enone intermediate in which this group is oriented trans- to the bulky $\mathrm{Ph}^{*}$ ketone. Decreasing the size of the $R_{L}$ substituent allows a mixture of
Table 1. Optimization of an enantioconvergent hydrogen borrowing alkylation. ${ }^{[a]}$

\begin{tabular}{|c|c|c|c|c|c|}
\hline & $\mathrm{Me}^{\mathrm{OH}}$ & $\frac{\mathrm{NaO} t_{5}}{{ }^{t} \mathrm{BuOH}(3 \mathrm{I}}$ & $\begin{array}{l}4 \text { mol\%) } \\
\underset{\text { mol\%) }}{(4 \text { equiv) }} \\
110^{\circ} \mathrm{C}, 24 \mathrm{~h}\end{array}$ & & \\
\hline Entry & [M] $4 \mathrm{~mol} \%$ & Ligand & Base & Yield $^{[b]}$ & e.r. ${ }^{[c]}$ \\
\hline 1 & $\operatorname{Ir}(\mathrm{cod}) \mathrm{acac}$ & 4 & $\mathrm{Na}^{t} \mathrm{OBu}$ & (91) & $90: 10$ \\
\hline 2 & $\operatorname{lr}(\mathrm{cod}) \mathrm{acac}$ & 5 & $\mathrm{Na}^{t} \mathrm{OBu}$ & 16 & $59: 41$ \\
\hline 3 & $\operatorname{lr}(\mathrm{cod}) \mathrm{acac}$ & 6 & $\mathrm{Na}{ }^{t} \mathrm{OBu}$ & 88 & $81: 19$ \\
\hline 4 & $\operatorname{Ir}(\mathrm{cod}) \mathrm{acac}$ & 7 & $\mathrm{Na}^{t} \mathrm{OBu}$ & 93 & $68: 32$ \\
\hline 5 & $\operatorname{Ir}(\operatorname{cod})$ acac & 8 & $\mathrm{Na}^{t} \mathrm{OBu}$ & 64 & $79: 21$ \\
\hline 6 & $\operatorname{Ir}(\mathrm{cod}) \mathrm{acac}$ & 9 & $\mathrm{Na}^{t} \mathrm{OBu}$ & 45 & $50: 50$ \\
\hline 7 & $\operatorname{Ir}(\operatorname{cod})$ acac & 10 & $\mathrm{Na}^{t} \mathrm{OBu}$ & 13 & $58: 42$ \\
\hline 8 & {$[\mathrm{Rh}(\operatorname{cod}) \mathrm{Cl}]_{2}$} & 4 & $\mathrm{Na}^{t} \mathrm{OBu}$ & 44 & $50: 50$ \\
\hline 9 & {$[\mathrm{Ru}(\operatorname{cod}) \mathrm{Cl}]_{\mathrm{n}}$} & 4 & $\mathrm{Na}^{t} \mathrm{OBu}$ & 62 & $77: 23$ \\
\hline 10 & $\operatorname{Ir}(\mathrm{cod}) \mathrm{acac}$ & 4 & $\mathrm{NaOH}$ & 0 & - \\
\hline 11 & $\operatorname{lr}(\mathrm{cod}) \mathrm{acac}$ & 4 & $\mathrm{KOH}$ & 16 & $78: 22$ \\
\hline 12 & $\operatorname{Ir}(\mathrm{cod}) \mathrm{acac}$ & 4 & $\mathrm{~K}^{t} \mathrm{OBu}$ & 19 & $90: 10$ \\
\hline
\end{tabular}

[a] Reaction conditions: 1 (1 equiv), alcohol (2 equiv), [Ir] (4 mol\%), ligand (5 mol\%), Base (4 equiv), ${ }^{\mathrm{t}} \mathrm{BuOH}(3 \mathrm{M}), 110^{\circ} \mathrm{C}, 24 \mathrm{~h}$. [b] Determined by reverse phase HPLC analysis vs durene as an internal standard; values in parentheses indicate the yield of isolated product. [c] Determined by normal phase HPLC analysis using a chiral stationary phase. cod $=1,5$ cyclooctadiene; acac = acetylacetonate; DTBM = 3,5-di-tert-butyl-4methoxyphenyl.

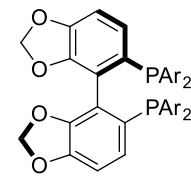

4: $\mathrm{Ar}=\mathrm{DTBM}$ 5: $\mathrm{Ar}=\mathrm{Ph}$

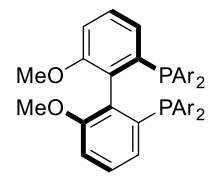

6: $\mathrm{Ar}=\mathrm{DTBM}$

7: $\mathrm{Ar}=3,5-{ }^{\mathrm{t}} \mathrm{Bu}_{2}-\mathrm{C}_{6} \mathrm{H}_{3}$

8: $\mathrm{Ar}=3,4,5-(\mathrm{OMe})_{3}-\mathrm{C}_{6} \mathrm{H}_{2}$

9: $\mathrm{Ar}=\mathrm{Ph}$

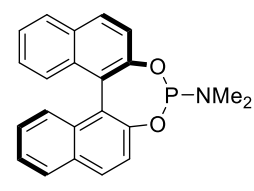

10 enone isomers to form and therefore leads to reduced enantioselectivity. In line with this hypothesis, decreasing the size of $R_{\mathrm{L}}$ further led to an additional decrease in enantioselectivity and ethyl substituted ketone $3 \mathrm{c}$ was obtained in 58:42 e.r. To probe this effect more systematically, we investigated a series of cycloalkane substituents with increasing ring size. Cyclopropyl, cyclobutyl and cyclopentyl substituted ketones (3d-3f) were isolated in 72:28, 78:22, $84: 16$ e.r. respectively. This result supports the hypothesis that bulkier substituents are able to bias the formation of isomerically pure enones more effectively. Similarly high enantioselectivity was observed with a cyclohexyl substituent and $\mathbf{3 g}$ was isolated in 82:18 e.r. in excellent yield. Pleasingly, introduction of a geminal dimethyl group at the $\beta$-position also enabled geometric control of the enone and afforded $\beta$ substituted ketone $3 \mathrm{~h}$ with 82:18 e.r. Other all carbon quaternary groups were equally well tolerated enabling the synthesis of $\beta$-substituted ketones $\mathbf{3} \mathbf{i}$ and $\mathbf{3} \mathbf{j}$ with high levels of enantioselectivity. This sense of enantioselectivity was proven for $3 a$ (vide infra) and the remaining compounds are assigned by analogy. 


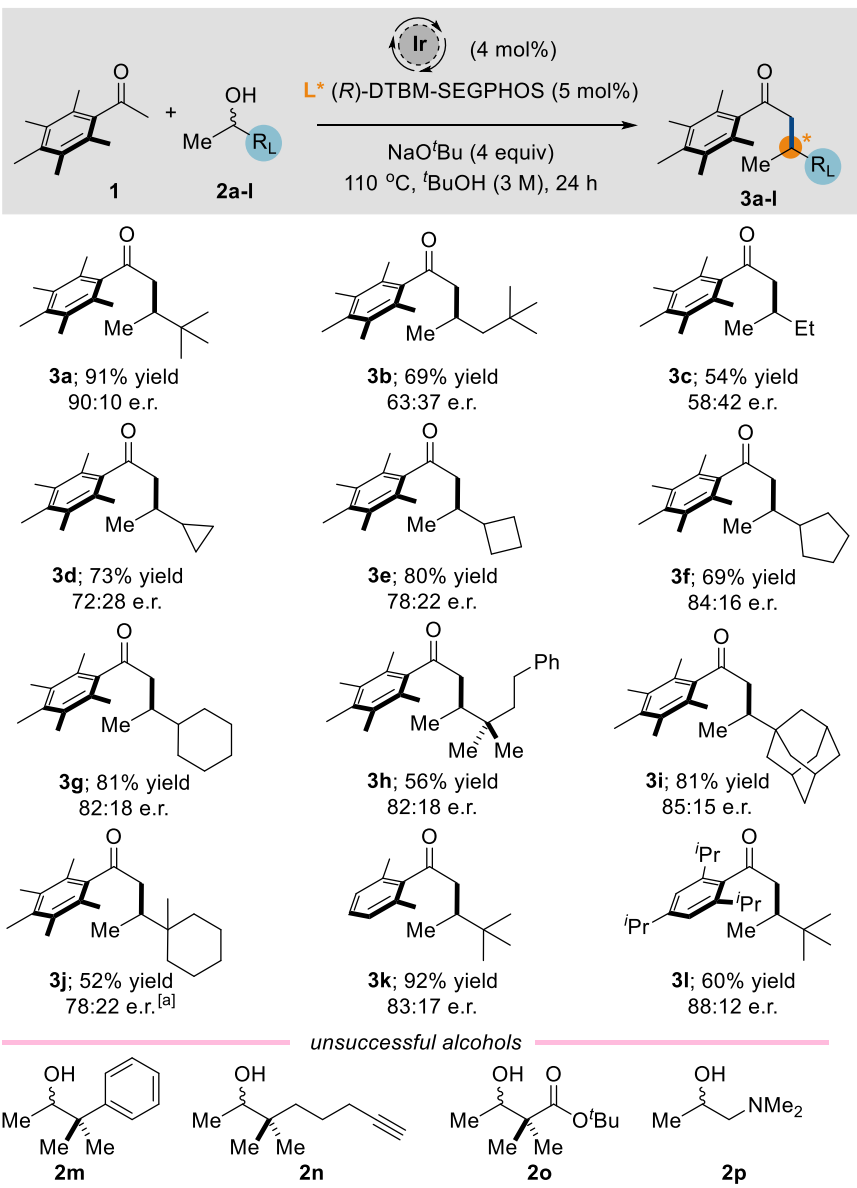

Scheme 2. Substrate scope for enantioconvergent hydrogen borrowing alkylation. Reaction conditions: aryl ketone (1 equiv), alcohol (2 equiv), Ir(cod)acac (4 mol\%), (R)-DTBM-SEGPHOS (5 mol\%), $\mathrm{NaO}{ }^{t} \mathrm{Bu}$ (4 equiv), ${ }^{t} \mathrm{BuOH}(3 \mathrm{M}), 110{ }^{\circ} \mathrm{C}, 24 \mathrm{~h}$. Yields refer to isolated material after column chromatography. Enantioselectivity determined by normal phase HPLC analysis using a chiral stationary phase. [a] Reaction time of $48 \mathrm{~h}$.

We have previously shown that the pentamethylphenyl ( $\left.\mathrm{Ph}^{*}\right)$ group is essential to the efficacy of this methodology. The bulky nature of the $\mathrm{Ph}^{*}$ group forces the carbonyl into the orthogonal plane, preventing unwanted reduction and homodimerization processes. ${ }^{10,12}$ However, we were pleased to find that variations of $\mathrm{Ph}^{*}$ are also tolerated. For example, 2,6-dimethylacetophenone underwent alkylation to afford 3k in $92 \%$ yield and 83:17 e.r. Substitution with a more bulky isopropyl substituent was also well tolerated, providing $\mathbf{3} \mathbf{l}$ in 88:12 e.r. Not all of the alcohols we investigated underwent the desired enantioconvergent alkylation process. For example, with a sterically encumbered phenyl substituted alcohol $\mathbf{2 m}$ only unreacted starting materials were observed after $24 \mathrm{~h}$. Attempts at alkylation with alcohols substituted with alkynes (2n), esters (2o) or amine groups (2p) were also unsuccessful and resulted in a complex mixture of products.

The enantioconvergent hydrogen borrowing alkylation could readily be performed on gram scale with no reduction in efficiency, enabling the synthesis of $3 a$ in $85 \%$ yield and 92:8 e.r. (Scheme 3A). Moreover, the highly crystalline nature of $\mathrm{Ph}^{*}$ containing compounds enabled stereoselective crystallization of the product and we were delighted to find the enantiomeric purity could be increased to $97: 3$ e.r. with $71 \%$ recovery. We have recently shown that under acidic conditions the $\mathrm{Ph}^{*}$ group can be efficiently cleaved to the corresponding carboxylic acid via a retro-Friedel-Crafts acylation. ${ }^{13}$ Applying these conditions to 3 a resulted in smooth cleavage to form enantioenriched carboxylic acid $\mathbf{1 1}$ in 93\% yield (Scheme 3B). Comparison of the specific rotation value of $\mathbf{1 1}$ to that previously reported in the literature allowed us to determine that the absolute stereochemistry of $\mathbf{1 1}$ (and therefore by extension 3a) is (S). ${ }^{14}$ Cleavage of the $\mathrm{Ph}^{*}$ group is also possible via a retro-Friedel-Crafts acylation reaction with bromine to form the acid bromide, which is a versatile intermediate that can react with a range of nucleophiles. For example, treatment of $\mathbf{3 a}$ with $\mathrm{Br}_{2}$ followed by $\mathrm{LiAlH}_{4}$ afforded primary alcohol 12 in $92 \%$ yield (Scheme $3 C$ ). Formation of the acid bromide followed by addition of either enantiomer of menthol yielded the corresponding diastereomeric esters, 13 and 14 , in $90 \%$ and $87 \%$ yield, respectively. Both 13 and 14 were isolated as single diastereomers, which confirms that the $\mathrm{Ph}^{*}$ cleavage proceeds with no epimerization at the $\beta$ stereogenic centre. In a similar manner, addition of enantiomeric chiral amine nucleophiles gave diastereomeric

A. Gram scale enantioconvergent alkylation followed by recrystallization

$$
\begin{aligned}
& \text { 1(0.95 g) } \\
& \text { recrystallization }[\mathbf{3 a} ; 85 \% \text { yield }(1.17 \mathrm{~g}) \\
& (71 \% \text { recovery }) \rightarrow 97: 3 \text { e.r. }
\end{aligned}
$$

B. $\mathrm{Ph}^{*}$ cleavage enables determination of absolute stereochemistry

$$
\text { 3a: } 97: 3 \text { e.r. }
$$

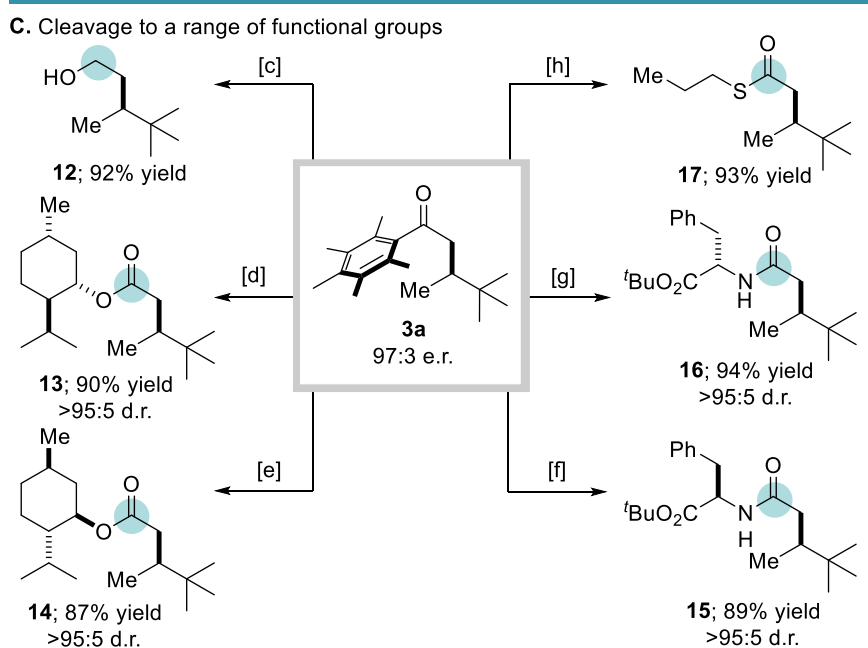

Scheme 3. Gram scale enantioconvergent hydrogen borrowing alkylation and cleavage of $\mathrm{Ph}^{*}$ ketone products. [a] 1 (1 equiv), 2a (2 equiv), Ir(cod)acac (4 mol\%), (R)-DTBM-SEGPHOS (5 mol\%), $\mathrm{NaO}^{t} \mathrm{Bu}$ (4 equiv), ${ }^{t} \mathrm{BuOH}(3 \mathrm{M}), 110{ }^{\circ} \mathrm{C}, 24 \mathrm{~h}$. Recrystallization from boiling $\mathrm{MeOH}$. [b] 3a (1 equiv, $0.2 \mathrm{mmol}$ ), $2 \mathrm{M} \mathrm{HCl}$ in $\operatorname{HFIP}(2 \mathrm{~mL}), 65^{\circ} \mathrm{C}$. [c] $\mathrm{Br}_{2}$ (2 equiv), $\mathrm{CH}_{2} \mathrm{Cl}_{2}$, $17{ }^{\circ} \mathrm{C}$ then $\mathrm{LiAlH}_{4}$ (5 equiv), THF, r.t. [d] $\mathrm{Br}_{2}$ (2 equiv), $\mathrm{CH}_{2} \mathrm{Cl}_{2},-17{ }^{\circ} \mathrm{C}$ then Dmenthol (3 equiv), r.t. [e] $\mathrm{Br}_{2}$ (2 equiv), $\mathrm{CH}_{2} \mathrm{Cl}_{2},-17{ }^{\circ} \mathrm{C}$ then L-menthol (3 equiv), r.t. [f] $\mathrm{Br}_{2}$ (2 equiv), $\mathrm{CH}_{2} \mathrm{Cl}_{2},-17{ }^{\circ} \mathrm{C}$ then $\mathrm{H}-\mathrm{D}-\mathrm{Phe}-\mathrm{O}^{t} \mathrm{Bu} . \mathrm{HCl}$ (2 equiv), ${ }^{i} \mathrm{PrEt}_{2} \mathrm{~N}$ (4 equiv), r.t. [g] $\mathrm{Br}_{2}$ (2 equiv), $\mathrm{CH}_{2} \mathrm{Cl}_{2},-17{ }^{\circ} \mathrm{C}$ then $\mathrm{H}-\mathrm{L}-\mathrm{Phe}-\mathrm{O}^{t} \mathrm{Bu}$. $\mathrm{HCl}$ (2 equiv), ${ }^{i} \operatorname{PrEt}_{2} \mathrm{~N}$ (4 equiv), r.t. [h] $\mathrm{Br}_{2}$ (2 equiv), $\mathrm{CH}_{2} \mathrm{Cl}_{2},-17{ }^{\circ} \mathrm{C}$ then propane-1-thiol (3 equiv), r.t. 
amides 15 and 16, as single diastereomers in excellent yields. Finally treatment of $\mathbf{3 a}$ with bromine followed by addition of propane-1-thiol afforded thioester 17 in 93\% yield.

We rationalise the absolute stereochemical outcome of the enantioconvergent hydrogen borrowing reaction through $\mathrm{Si}$ face coordination of the s-cis enone intermediate to the chiral iridium hydride complex (Figure 1). This places the steric bulk of the $\mathrm{Ph}^{*}$ group in the open quadrant of the complex. The competing Re-transition state is strongly disfavoured by steric clash with the P-Ar group of the ligand. This mode of induction is analogous to the enantioselective cyclic hydrogen borrowing reaction, which was supported by computational studies. ${ }^{10 a}$

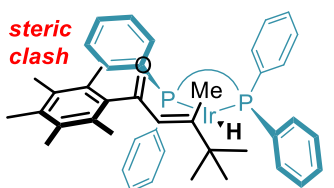

Re-TS (disfavoured)

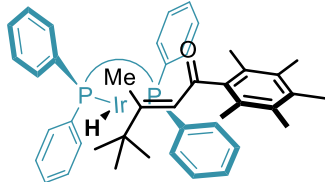

Si-TS (favoured)
Figure 1. Rationalization of absolute stereochemistry of the enantioconvergent hydrogen borrowing alkylation reaction.

In summary, we have developed a synthesis of $\beta$-branched acyclic ketones via enantioconvergent alkylation of ketones with unactivated secondary alcohols. Using commercially available $[\operatorname{Ir}(\mathrm{cod}) \mathrm{acac}]$ and $(R)$-DTBM SEGPHOS, this process is able to efficiently form sterically hindered $\mathrm{C}\left(\mathrm{sp}^{3}\right)-\mathrm{C}\left(\mathrm{sp}^{3}\right)$ carbon bonds in excellent yields. The $\mathrm{Ph}^{*}$ ketone products can be derivatized to a variety of functional groups without any racemization of the newly installed stereogenic centre.

D.M.J.C. is grateful to the EPSRC Centre for Doctoral Training in Synthesis for Biology and Medicine (EP/L015838/1) for a studentship, generously supported by AstraZeneca, Diamond Light Source, Defence Science and Technology Laboratory, Evotec, GlaxoSmithKline, Janssen, Novartis, Pfizer, Syngenta, Takeda, UCB and Vertex. D.M.J.C. also thanks the Oxford-Radcliffe Scholarship for a studentship. We thank the EPSRC [W.M.A., R.J.A., and T.J.D., (EP/L023121/1 and EP/R513295/1)] for financial support. R.J.A is also grateful to University College, Oxford for a Junior Research Fellowship.

\section{Conflicts of interest}

There are no conflicts to declare.

\section{Notes and references}

1 Mathias Christmann, Stefan Bräse, Asymmetric Synthesis: The Essentials, $2^{\text {nd }}$ Edition, Wiley, Chichester, 2007.

2 (a) V. Bhat, E. R. Welin, X. Guo and B. M. Stoltz, Chem. Rev. 2017, 117, 4528-4561; (b) J. T. Mohr, J. T. Moore and B. M. Stoltz, Beilstein J. Org. Chem., 2016, 12, 2038-2045.

3 (a) B. M. Trost, J. Org. Chem., 2004, 69, 5813-5837; (b) Q. Cheng, H.-F. Tu, C. Zheng, J.-P. Qu, G. Helmchen and S.-L. You, Chem. Rev., 2019, 119, 1855-1969; (c) S. L. Rössler, D. A. Petrone and E. M. Carreira, Acc. Chem. Res., 2019, 52 2657-2672. (d) H. You, E. Rideau, M. Sidera and S. P. Fletcher, Nature, 2015, 517, 351-355.

4 (a) G. C. Fu, ACS Cent. Sci., 2017, 3, 692-700; (b) J. Choi and G. C. Fu, Science, 2017, 356, eaaf7230; (c) A. H. Cherney, N. T. Kadunce and S. E. Reisman, Chem. Rev., 2015, 115, 95879652.
5 (a) M. A. Emmanuel, N. R. Greenberg, D. G. Oblinsky and T. K. Hyster, Nature, 2016, 540, 414-417; (b) Q. M. Kainz, C. D. Matier, A. Bartoszewicz, S. L. Zultanski, J. C. Peters and G. C. Fu, Science, 2016, 351, 681-684; (c) J. Li, M. Kong, B. Qiao, R. Lee, X. Zhao and Z. Jiang, Nat Commun, 2018, 9, 1-9.

6 Y. Zhang, C.-S. Lim, D. S. B. Sim, H.-J. Pan and Y. Zhao, Angew. Chem. Int. Ed., 2014, 53, 1399-1403.

7 For related work, see: (a) Z.-Q. Rong, Y. Zhang, R. H. B. Chua, H.-J. Pan and Y. Zhao, J. Am. Chem. Soc., 2015, 137, 49444947; (b) M. Peña-López, H. Neumann and M. Beller, Angew. Chem. Int. Ed., 2016, 55, 7826-7830; (c) P. Yang, C. Zhang, Y. Ma, C. Zhang, A. Li, B. Tang and J. S. Zhou, Angew. Chem. Int. Ed., 2017, 56, 14702-14706; (d) C. S. Lim, T. T. Quach and Y. Zhao, Angew. Chem. Int. Ed., 2017, 56, 7176-7180. (e) G. Xu, G. Yang, Y. Wang, P.-L. Shao, J. N. N. Yau, B. Liu, Y. Zhao, Y. Sun, X. Xie, S. Wang, Y. Zhang, L. Xia and Y. Zhao, Angew. Chem. Int. Ed. 2019, 58, 14082-14088; (f) F. G. Mutti, T. Knaus, N. S. Scrutton, M. Breuer and N. J. Turner, Science, 2015, 349, 1525-1529.

8 For representative reviews of hydrogen borrowing catalysis, see: (a) G. E. Dobereiner, R. H. Crabtree, Chem. Rev. 2010, 110, 681-703; (b) S. Bähn, S. Imm, L. Neubert, M. Zhang, H. Neumann, M. Beller, ChemCatChem 2011, 3, 1853-1864; (c) S. Pan, T. Shibata, ACS Catal. 2013, 3, 704-712; (d) C. Gunanathan, D. Milstein, Science 2013, 341, 1229712; (e) Y. Obora, ACS Catal. 2014, 4, 3972-3981; (f) Q. Yang, Q. Wang, Z. Yu, Chem. Soc. Rev. 2015, 44, 2305-2329; (g) A. Nandakumar, S. P. Midya, V. G. Landge, E. Balaraman, Angew. Chem. Int. Ed. 2015, 54, 11022-11034; (h) J. Leonard, A. J. Blacker, S. P. Marsden, M. F. Jones, K. R. Mulholland, R. Newton, Org. Process Res. Dev. 2015, 19, 1400-1410; (i) A. Corma, J. Navas, M. J. Sabater, Chem. Rev. 2018, 118, 1410-1459; (j) M. Holmes, L. A. Schwartz, M. J. Krische, Chem. Rev. 2018, 118, 6026-6052.

9 For selected examples, see: (a) D. J. Shermer, P. A. Slatford D. D. Edney, J. M. J. Williams, Tetrahedron: Asymm. 2007, 18, 2845-2848. (b) T. Suzuki, Y. Ishizaka, K. Ghozati, D.-Y. Zhou, K. Asano, H. Sasai, Synthesis 2013, 45, 2134-2136. (c) G. Onodera, Y. Nishibayashi, S. Uemura, Angew. Chem. Int. Ed. 2006, 45, 3819-3822. (d) A. Quintard, T. Constantieux, J. Rodriguez, Angew. Chem. Int. Ed. 2013, 52, 12883-12887. Krische and co-workers have also reported related processes involving asymmetric carbometallation, see: (e) S. W. Kim, W. Zhang, M. J. Krische, Acc. Chem. Res. 2017, 50, 23712380; (f) J. M. Ketcham, I. Shin, T. P. Montgomery and M. J. Krische, Angew. Chem. Int. Ed. 2014, 53, 9142-9150.

10 (a) R. J. Armstrong, W. M. Akhtar, T. A. Young, F. Duarte and T. J. Donohoe, Angew. Chem. Int. Ed. 2019, 58, 1255812562. For the corresponding racemic reactions, see: (b) W. M. Akhtar, R. J. Armstrong, J. R. Frost, N. G. Stevenson and T. J. Donohoe, J. Am. Chem. Soc., 2018, 140, 11916-11920. (c) R. J. Armstrong, W. M. Akhtar, J. R. Frost, K. E. Christensen, N. G. Stevenson and T. J. Donohoe, Tetrahedron, 2019, 75, 130680.

11 (a) Z. Zhang, N. A. Butt, W. Zhang, Chem. Rev. 2016, 116 14769-14827; (b) T. L. Church, P. G. Andersson, Coord. Chem. Rev. 2008, 252, 513-531; (c) J. J. Verendel, O. Pàmies, M. Diéguez, P. G. Andersson, Chem. Rev. 2014, 114, 21302169.

12 (a) J. R. Frost, C. B. Cheong, W. M. Akhtar, D. F. J. Caputo, N. G. Stevenson and T. J. Donohoe, J. Am. Chem. Soc., 2015, 137, 15664-15667; (b) W. M. Akhtar, C. B. Cheong, J. R. Frost, K. E. Christensen, N. G. Stevenson and T. J. Donohoe, J. Am. Chem. Soc., 2017, 139, 2577-2580.

13 L. B. Smith, R. J. Armstrong, D. Matheau-Raven, T. J. Donohoe, J. Am. Chem. Soc., 2020, 142, 2514-2523.

14 E. Reyes, J. L. Vicario, L. Carrillo, D. Badía, U. Uria and A. Iza, J. Org. Chem., 2006, 71, 7763-7772. 